\title{
Current Use of Carbon-Based Materials for Biomedical Applications-A Prospective and Review
}

\author{
Govindasamy Rajakumar ${ }^{1}$, Xiu-Hua Zhang ${ }^{1, *}$, Thandapani Gomathi ${ }^{2, *}$, Sheng-Fu Wang ${ }^{1}$, \\ Mohammad Azam Ansari ${ }^{3}$, Govindarasu Mydhili ${ }^{4}$, Gnanasundaram Nirmala ${ }^{5}$, \\ Mohammad A. Alzohairy ${ }^{6}$ and Ill-Min Chung ${ }^{7, *}$ \\ 1 College of Chemistry and Chemical Engineering, Hubei University, Wuhan 430062, China; \\ microlabsraj@gmail.com (G.R.); wangsf@hubu.edu.cn (S.-F.W.) \\ 2 Department of Chemistry, D.K.M. College for Women, Vellore 632001, Tamil Nadu, India \\ 3 Department of Epidemic Disease Research, Institutes for Research and Medical Consultations (IRMC), \\ Imam Abdulrahman Bin Faisal University, Dammam 31441, Saudi Arabia; azammicro@gmail.com \\ 4 Department of Biochemistry, Periyar University, Salem 636011, Tamil Nadu, India; mydhilibc12@gmail.com \\ 5 Mass Transfer lab, School of Chemical Engineering, VIT University, Vellore 632014, Tamil Nadu, India; \\ gsnirmala@vit.ac.in \\ 6 Department of Medical Laboratories, College of Applied Medical Sciences, Qassim University, Qassim 51431, \\ Saudi Arabia; dr.alzohairy@gmail.com \\ 7 Department of Crop Science, College of Sanghuh Life Science, Konkuk University, Seoul 05029, Korea \\ * Correspondence: zhangxh@hubu.edu.cn (X.-H.Z.); chemist.goms@gmail.com (T.G.); \\ imcim@konkuk.ac.kr (I.-M.C.); Tel.: +86-133-4983-3448 (X.-H.Z.); +91-63852-13912 (T.G.); \\ +82-105-470-8301 (I.-M.C.)
}

Received: 25 November 2019; Accepted: 11 March 2020; Published: 20 March 2020

\begin{abstract}
Among a large number of current biomedical applications in the use of medical devices, carbon-based nanomaterials such as graphene (G), graphene oxides (GO), reduced graphene oxide $(\mathrm{rGO})$, and carbon nanotube $(\mathrm{CNT})$ are frontline materials that are suitable for developing medical devices. Carbon Based Nanomaterials (CBNs) are becoming promising materials due to the existence of both inorganic semiconducting properties and organic $\pi-\pi$ stacking characteristics. Hence, it could effectively simultaneously interact with biomolecules and response to the light. By taking advantage of such aspects in a single entity, CBNs could be used for developing biomedical applications in the future. The recent studies in developing carbon-based nanomaterials and its applications in targeting drug delivery, cancer therapy, and biosensors. The development of conjugated and modified carbon-based nanomaterials contributes to positive outcomes in various therapies and achieved emerging challenges in preclinical biomedical applications. Subsequently, diverse biomedical applications of carbon nanotube were also deliberately discussed in the light of various therapeutic advantages.
\end{abstract}

Keywords: carbon-based nanomaterials; Graphene (G); Graphene Oxides (GO); reduced Graphene (rGO); Carbon NanoTube (CNT); biomedical applications

\section{Introduction}

Biomolecules or biomaterials have played a crucial role in clinical devices. Biomaterials in the form of nanomaterials have been introduced in various fields, particularly in clinical and biomedical research, for its nanoscale-sized property [1]. Among nanomaterials, Carbon-based nanomaterials received attention due to its high chemical resistance ability, efficient mechanical properties, and weightless character. Additionally, it has the highest rate of distribution ability in the body [2]. Graphene is one of the bionanomaterials that were used in the biomedical field. Carbon derivatives, such as few-layer graphenes, graphene oxide, carbon nanotubes, nano diamonds, and reduced graphene 
oxide [3], are exhaustively used in biomedical systems (Figure 1). Among the carbon nanomaterials, CNT represents a peculiar feature with combined properties of electrical, optical, and mechanical, which enable them to use different biomolecules, including drugs [4], thereby, received more attraction in biomedical applications. There are reports that when CNT is used alone, it will cause remarkable cytotoxic effects while modifying it into composite materials that are loaded with the biocompatible matrix, the reduction in toxicity was observed [5]. Therefore, in this review, we have focused on the current applications of nanomaterials, such as CNT, graphene, and its associated materials GO, rGO, in biomedical fields.

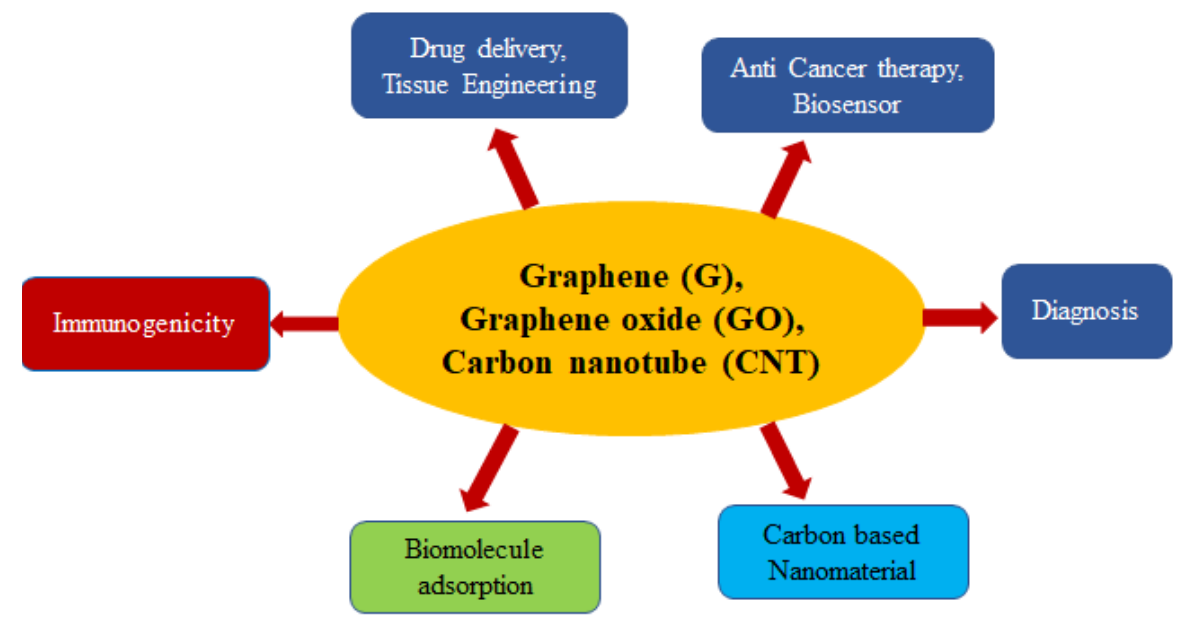

Figure 1. Biomedical applications of nano based materials.

\section{Graphene}

Carbon is one of the most plentiful components present in the earth's crust. Carbon was used in various kinds of significant applications in the diverse scientific paradigm. Carbon can exist in nature, in many allotropic forms, such as diamond, graphene, nanotube, fullerene, etc. [5]. Among them, Graphene $(\mathrm{G})$ is a unique allotropic form and is well known for its graphene layer (single or monolayer). The recent ISO Standard has defined them as a single layer of carbon atoms, which are covalently associated together and each carbon atom bound to three adjacent molecules, like a honeycomb model [6]. Graphene can be derived from graphite, which is composed of graphene layers heaped up to each other molecules in parallel, in three dimensions and crystalline nature [7].

Graphene (G) showed its unique characteristics, such as thermal, electrical, and mechanical, specifically in their 2D structure, and contributed unlimited potential and technical benefits. Additionally, it has a large surface area which was found to be $2630 \mathrm{~m}^{2} \mathrm{G}^{-1}$. Mobility exhibited graphene was $200,000 \mathrm{~cm}^{2} \mathrm{~V}^{-1} \cdot \mathrm{S}^{-1}$ [8] and it has great optical transmittance ability of approximately $\sim 97.7 \%$. Thermal conductivity was found as $\sim 5000 \mathrm{Wm}^{-1} \cdot \mathrm{K}^{-1}$ [9]. Graphene can act as a barrier to gases and liquid to penetrate [10]. Owing these properties, graphene-based materials exhibit its vital role in various fields, including drug delivery [11], tissue engineering [12,13], production of antibacterial strains [14], bio-sensing, gene delivery [15], cancer therapy [16], and other biomedical applications [13].

Graphene Oxide (GO) is a chemically modified form of graphene, modification that can be done by a method of oxidation, which leads to the introduction of the functional group - $\mathrm{CO}$ and -OH groups, on the planes or edges. The treatments, such as chemical, thermal, photochemical, and microbial can also be used on GO in order to reduce oxygen content, which results in reduced Graphene Oxide (rGO) [17]. A complete reduction of oxygen contributes a pure and perfect graphene layer as a final product. However, $\mathrm{sp}^{2}$ hybridized carbon converted during oxidation is impossible to revert to $\mathrm{sp}^{3}$ hybridization [18]. Graphene oxides are flexible to vary its geometry, like paper, fibers, and three-dimensional foam (Aerogels). 
Aerogels are solid systems with pores that prevalent open pores possess gas as a dispersed phase [19]. Graphene-based aerogels achieved a remarkable place in the Guinness World Records in 2015 [20]. Graphene-based aerogels that represent the sensitivity of $0.16 \mathrm{mg} / \mathrm{cm}^{3}$ are found to be $7.5 \times$ lighter thin air [21]. Higher stiffness (Hardness) has been measured as 10,000 times the preprocessed materials [22]. The lower thermal conductivity of heat due to the high porosity and randomly oriented structure and large specific surface are is able to function for particular substance adsorption, like oils [23]. Graphene in the form of aerogels is used as 2D drug delivery system and also in tissue engineering manipulations [24,25].

Graphene $(\mathrm{G})$ is hydrophobic, whereas GO is hydrophilic [26]. GO contains both aromatic $\left(\mathrm{sp}^{2}\right)$ and aliphatic $\left(\mathrm{sp}^{3}\right)$ domains, which further expands the surface of GO to permit $\pi-\pi$ interactions and electrostatic interaction with adjacent molecules. This peculiar character helps to allow for drug binding on its surface, which is helpful in drug delivery applications [27]. Liu et al. used PEGylated GO to transport a camptothecin analog [28].

\section{Carbon Nanotube (CNT)}

Nanomaterials are the organic or inorganic particles, nano-sized in the range of $0.1-100 \mathrm{~nm}$. Based on the National Academics Classification, nanoscale materials are grouped into four groups: (a) the metal oxides (b); nano clays (c); nanotubes; and, (d) Quantum dots [29]. According to the US Environmental Protection Agency (EPA), it was categorized as carbon-based materials, (b) metal-based, (c) Dendrimers, and (d) composites. Above all, carbon nanotubes (CNT) received attention from the scientific community. CNT is a long carbon chain, and each carbon atom bound to three carbon atoms forming $\mathrm{sp}^{2}$ hybridized carbon. It is noteworthy that $\mathrm{sp}^{2}$ hybridization is more powerful than the $\mathrm{sp}^{3}$ hybridization found in the diamond. Thereby, it exhibits peculiar strength with excellent thermal and electrical conductivity. In recent times CNTs have been used in several biomedical fields, such as tissue engineering, drug delivery, gene therapy, and acting as biosensors [30]. Furthermore, its commercial applications include electronic [31], optics [32], material sciences [33], and architecture [34]. The ability to alter chemical nature leads to biocompatibility that enables their use in the thrust areas of current biomedical research.

Particularly in drug delivery applications, the unique features of CNTs, like large expanded surface area, strong stability, and potential to conjugate with several therapeutic antibodies, DNA, enzymes, and to discharge of loaded drugs near the targeted cells $[35,36]$. The methods are used to carry drugs on the surface of CNTs or loaded into the CNT matrix. Among them, the internalization method is reportedly highly effective as a surface attachment. CNT carriers can pass the cells either by adopting the endocytosis mechanism or insertion or diffusion process. In the internalization method, after entering the drug conjugated complex into the cell, the intracellular environment destructs the complex and liberating therapeutic agent inside the cells. Nevertheless, in the surface attachment method, the drug is able to release before entering the internal environment in the body fluid. The mentioned approaches in drug delivery were first used to attach antineoplastic and antibiotic drugs to CNTs against cancer cells and infection therapy [35]. The mechanism of drug delivery while using $\mathrm{G} / \mathrm{GO}$ and its associates in the treatment of cancer has been discussed in the following section.

\section{Biomedical Applications}

\subsection{Anti-Cancer Drug Delivery Applications}

Cancer is a deadly dangerous disease and is a profound contributing factor to the increased death rates by several varieties of tumors [37]. It is noteworthy that, although cancer treatment has emerged and developed drastically, still unsuccessful outcomes are challenging, due to the poor bioavailability and poor delivery measure prevailing to the appropriate target site. Graphene-based materials are emerging as drug vehicles, cellular imaging agents, and sensors to overcome these obstacles in the treatment of cancer [16]. A simple methodology has been utilized by fabricating a nano-composite 
from GO and drugs. An investigation of Farahnaz Barahuie et al., has stated that the fabrication of $\mathrm{GO}$ as a drug carrier for chlorogenic acid (CA) can be administered as a pH-sensitive platform for the controlled discharge of CA from GO [38]. CA loaded GO showed a lesser and negligible toxic effect on normal cells, whereas highly toxic effects were observed towards cancer cell lines. Recent literature has underlined that folic acid with polyethyleneimine (PE1), functionalized GO, along with carboxymethyl cellulose, showed non-toxicity on normal cells and resulted in a controlled discharge of doxorubicin (Dox) [39]. Li et al. [20] have demonstrated that Folic acid, altogether with (PE1) functionalized GO used as a vehicle for two novel copper complexes to the nasopharyngeal cancer cell lines (HNE1) for discharging drugs in a sustained manner.

The formulation of hydrophobic anticancer drugs using the hydrogels of GO-based nanofillers in order to bind drugs and delivered drug in the controlled release manner is another related strategy used in cancer therapy [40]. G/GO-based hydrogels that were loaded with camptothecin and doxorubicin were also reported [41]. This complex of hydrogels was capable of liberating anticancer drugs dead slow than Pluronic F-127 solution indicating high binding interaction of hydrophobic drugs attributable to the G/GO contains in the gels. Another research group has emphasized that rGO (reduced graphene oxide) with AgNP (Silver Nanoparticles) stimulated the enhanced generation of free radicals (ROS) in A549 lung cancer cells, leading to an attack on phospholipids that are resulting cell death through apoptosis. These composites can minimize the number of ovarian cancer stem cells (OVSCS) that are responsible for acute tumorigenicity (Table 1) [42].

Graphene materials are majorly used as drug carriers due to their versatile chemical nature and biocompatibility with expanded surface area $[43,44]$. Few Layers Graphenes (FLG) dispersions can attack monocytes by affecting neither toxic nor activation consequences on the immunocompetent cells. Such therapeutic action of FLG had been tested in cancer, such as Myelomonocytic leukemia, wherein monocytes are prevailing in tumor form. The results demonstrated that FLG has been considered an active factor in the necrosis of monocytic cancer cells. Further, an analysis of FLG effects as compared with popular drugs, etoposide substantially exerted its effectiveness in anti-cancer activity [45]. Graphene nanosponge has fabricated dual chemotherapeutics loaded sponge-like carbon and used as a supported lipid bilayer along with tumor-targeting protein, showed the successful suppression of the xenograft tumors in 16 days [46].

Several investigations have been carried out and extensively studied in GO as a drug delivery carrier. In GO preparation, using Hummer's single layer and few-layer GO, undesired graphite oxide, and pristine graphite, indeed, these materials can be separated [47]. The GO faction can be segregated according to the lateral dimension to perform the delivery function, such as leading capacity, adsorption kinetics, and cytotoxicity based on their size, to achieve high quality [48].

In vivo applications of GO, materials are categorized based on passive targeting and increased permeability and retention effects. These effects commonly occur in several tumor tissues, which are attributed to the high vascularisation. Hence, the active targeting of GO has paved the way to accumulating nanomaterials to the target cancer tissue, improving its efficacy and reducing side effects [43,49]. Nasrollahi et al. studied transferrin (Tf) and poly (allamine hydrochloride) (PAH) in modified GO for docetaxel delivery on MCF-5 cells with high efficiency (Figure 2) [50]. Utilizing the rationally structured type of GO nanomatrix in the form of carrier, diagnosing agents and therapeutic agents for accurate tumor treatment shows that GO has a splendid future in nanomedicine, yet there are still some essential concerns and urgent difficulties regarding further clinical application [51]. 

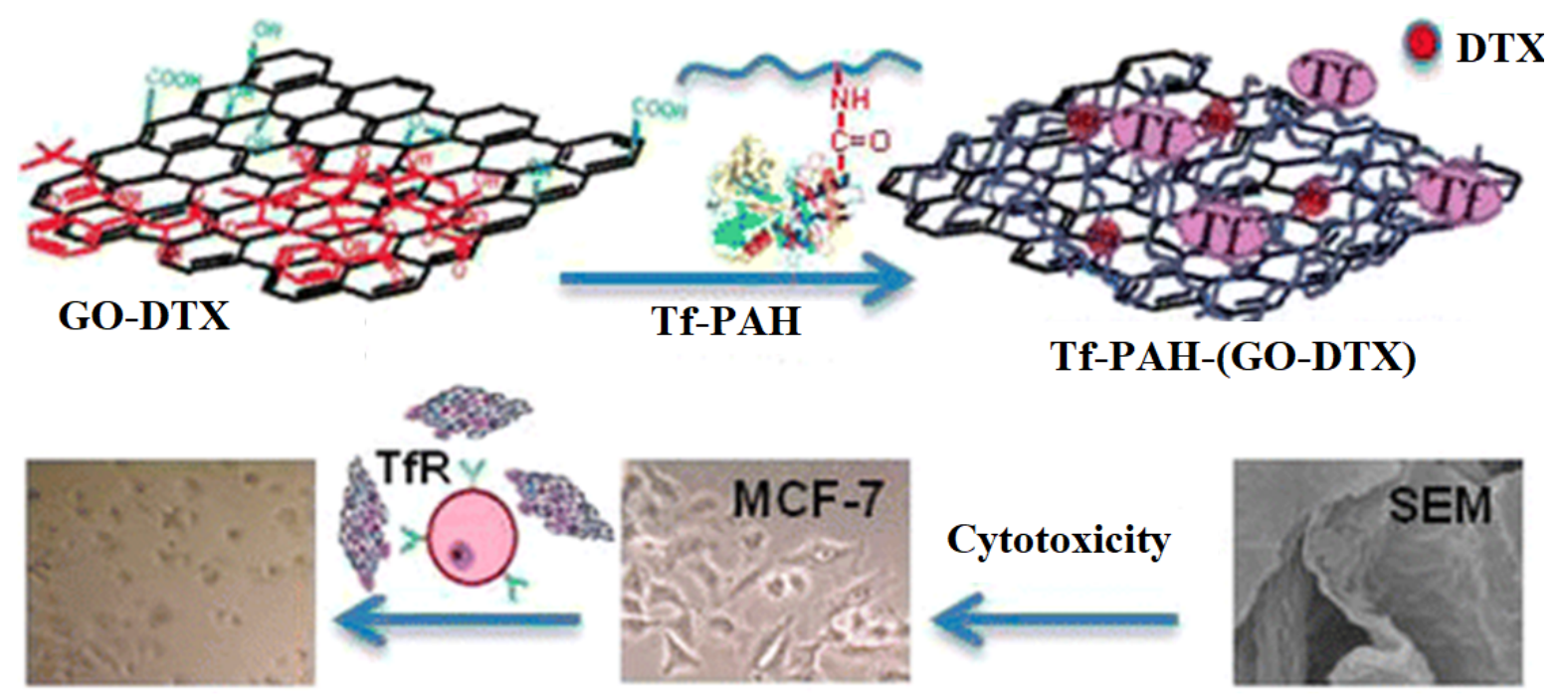

Figure 2. Transferrin-poly (allamine hydrochloride) (Tf-PAH) modified Graphene Oxide (GO) for docetaxel (DTX) delivery. [50,51] Reprinted with permission from Elsevier.

Generally, in GO-based materials, lipohilic drugs bonded to less polar sites, whereas targeting protein molecules covalently interacted with GO. This provides a combined effect on the drug uptake/discharge for controlled drug delivery. Further, the functionalization of GO will enhance the dispersing ability of GO in aqueous or cell media by improving its non-toxic nature towards cell tissues and stimulating the adhesion of the cancer cells or tissues. The intracellular environment is an important factor in drug delivery. Cellular environment, mainly the cellular matrix and cytoplasm, will alter drug discharge in a cell. Especially, the $\mathrm{pH}$ of the cellular matrix affects drug release, while lowering the $\mathrm{pH}$ drug release can be facilitated from GO. For example, in the case of doxorubicin loaded GO, amino functional group induce destabilization thereby affinity with GO sheets.

CNTs have shown to be better pharmacological and therapeutic profiles of drug molecules. The capability of functionalized CNT to enter into the cells helps in delivering small drug molecules in a dose based manner $[52,53]$ CNT outer surfaces can be altered to enhance its solubility and susceptibility, and drug insertion could be achieved through inner hollow core [54]. The use of CNTs in cancer therapy is widely approved and they are incapable of targeting the malignant tumor due to the best intake by a specific section of malignant cells, without eroding and affecting healthy cells. Proto et al. demonstrated that CNTs could escape from cellular immune reaction and phagocytosis as an external invader [55]. CNT discharge the drugs to target cancer cells while using enhanced permeability and retention effects [56]. Since its nanoscale size, CNT can intrude inside the tumor blood vessels. In a normal cell, the size of the pores in the blood vessels is found to be $(2-6 \mathrm{~nm})$, whereas a tumor tissue (100-800 nm) [32]. Therefore, nanoparticles' size range from 100-700, being unable to invade healthy tissue, blood vessels, while in the tumor target site, it can be accumulated. Polyethylene glycol activated CNTs can be conjugated with a widely used paclitaxel drug by making an amide bond between the PEG chain with paclitaxel and suppressed cancer development in the mice model [57].

Another study reported that PEG was often used to functionalize single-walled CNTs (SWCNT) and become the SWCNT-PEG complex that caused no toxicity effects in mice over a long period after intravenous injection. The retention in the blood circulation of the SWCNT-PEG complex is significant $(81.4 \pm 7.4 \mathrm{~min}$. $)$ when compared with paclitaxel. Its duration was found to be $(18.8 \pm 1.5 \mathrm{~min}$. $)$ and PEG-coated paclitaxel has been recorded as (22.8 $\pm 1.0 \mathrm{~min}$.). The study findings suggested that increased EPR effects, long time circulation, the best delivery ability, and tumor suppression is overcome by SWCNT-PTX for 471 animal model and believed to be resistance to Paclitaxel treatment [58] BBB, formed by endothelial cells, astrocytes, and pericytes could prevent the entering of therapeutic molecules into the central nervous system (CNS), resulting in the failure of treatment of brain diseases (Figure 3). The treatment of the in vitro blood brain barrier (BBB) model with Multi-walled 
CNTs-fluorescein isothiocyanate (MWCNT-FITC) did not induce cytotoxicity, changes of tight junction proteins, or transendothelial electric resistance (TER), which suggested the biocompatibility. However, MWCNT-FITC could form aggregation that was driven by van der Waals forces, which should be decreased by, for example, surface functionalization with molecules other than FITC [59].

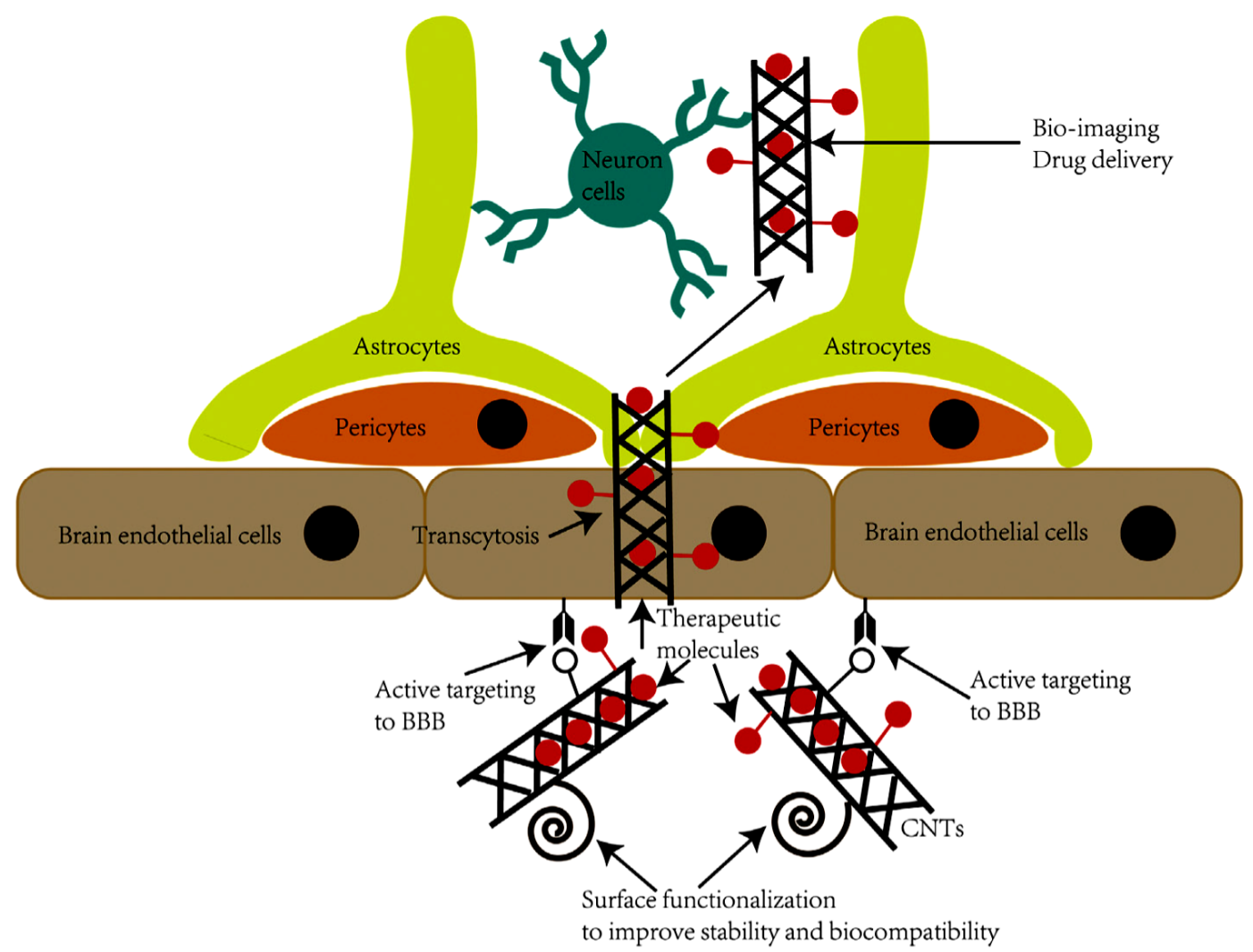

Figure 3. The strategy of the utilization of carbon nanotubes (CNTs) to cross the blood brain barrier (BBB). CNTs could be functionalized to increase the stability, biocompatibility, and active targeting of CNTs to BBB and nerve cells. Functionalized CNTs could effectively penetrate BBB and enter CNS for bio-imaging and drug delivery [59]. Reprinted with permission from Elsevier.

Several commonly used anti-cancer drugs, such as doxorubicin, paclitaxel, quercetin, cisplatin, and doxorubicin were conjugated with CNTs successfully and evaluated both in vitro and in vivo [30]. Interestingly, CNTs showed unique in targeting the drug in varied tumor cells. Taghdisi et al. demonstrated that a complex of Sgc8 aptamer, daunorubicin, and SWCNT are contributing to being internalized into T Cell leukemia of Humans (MOLT-4 Cells) [60]. An effective drug delivery system has been used for the systemic pioneering of doxorubicin, with chitosan, and folic acid-modified SWCNT, resulting in cell death in hepatocellular carcinoma SMMC-7721 cell lines with liver cancer and control doxorubicin [61]. The feature of exhibiting less toxicity than in vitro studies emphasized that CNTs are used as vehicles and they are capable of use in antitumor immunotherapy. The conjugation of CNTs with immunogens can stimulate immune-mediated T cells. Positively charged antigens have such effects on the surface and CNTs due to negative charge [62]. Su et al. [63] have developed iRGD-polyethyleneimine (PE1) functionalized MWCNT, which is subsequently conjugated with candesartan (CD). This complex is involved in targeting the tumor endothelium and lung tumor cells of the VB3-integrin and AT1R with the plasmid AT (2) [P4T (2)], IRGD, and CD, respectively. Condesartan has demonstrated a combined regulation of VEGF synergistic with PAT (2) and effectively suppresses angiogenesis.

While targeting tumor cells, drugs would be bound with a complex of CNT and antibody against an antigen present on the surface of cancer cells. This method is limited to carry tumor cells. In another 
method, drugs can be conjugated with a magnetic CNT complex, which is derived by adding a layer of magnetite $\left(\mathrm{Fe}_{3} \mathrm{O}_{4}\right)$ nanoparticles on the surface of the CNTs. This kind of conjugated complex was controlled by an external magnet to reach target cells [64]. With its tiny nanoscaled size, CNTs is accessible to external surface modification, and it can cross BBB by using various mechanisms to approach brain tumor therapy [65]. CNTs exhibited its uniqueness in targeting the drug in several tumors. To treat breast cancer, a water-soluble SWCNT-paclitaxel (PTX) conjugates are found to be highly effective in inhibiting the growth of rumor when comparing with Taxol in $4 \mathrm{~T}^{\prime} 1$ breast cancer cell model. In this trial, both showed extended circulation, increased permeability, and retention effects were detected [66].

A research group has demonstrated that CNTs can be participated and applied in antitumor immunotherapy [67]. In these approaches, the patient's immune system has been induced to kill malignant tumor cells that can be targeted by injecting cancer vaccines as drugs.

\subsection{Biosensing Applications}

In the field of biosensing technology, graphene-based materials have been used as biosensors. Based on diverse sensing mechanisms, such as optical and electrochemical signaling, which has been generated from graphene [68]. The recent electrochemical technique is reportedly one of the best methods to detect biomolecules [69], due to its ability, such as simple operation, sensitivity quick feedback, and inexpensive. Moreover, Graphene showed excellent electrocatalytic activity on $\mathrm{H}_{2} \mathrm{O}_{2}$ and enables them, and it will be used as electrode materials for oxidase based biosensors. The identification of glucose levels in diabetic patients is a vital indicator of clinical settings. Similar to this, the electrochemical detection of glucose in the blood could be assessed while using glucose oxidase as an indicator element [70].

Dan du et al. reported that graphene sheets could act as immune sensors during signal amplification and multi-enzyme activity for cancer. Additionally, the sensors showed seven-fold elevation with graphene modification and nanosphere adsorption [71]. This application is highly useful in identifying tumor biomolecular and improved diagnostics.

Electrical sensors are represented for the detection of macromolecules like protein. These sensors are working, based on immunoassays that are similar to the specificity of antigen/antibody affinities. The benefits of using graphene as the transducing platform were endorsed, due to improved electron transfer being a characteristic feature of graphene that can be used in electrochemical measurements, and multifactorial detections can be achieved with reduced graphene oxide (rGO) modified electrodes. For instance, electrochemical immune sensors that parallel detects two types of antigens, the carcinoembryonic marker, and squamous cancer antigen. This sensor is developed based on a glassy carbon electrode (GCE) that is modified with covalently animated reduced graphene oxide wherein immobilized antibodies are established [72]. Dong et al. investigated ZnPc (zinc phthalocyanine) drug delivery while using PEGylated GO via photodynamic therapy effectively in vitro towards the MCF-7 carcinoma cell line [73].

Sahu et al. [74] reported the combined photodynamic and photothermal therapy of Pluronic F127 modified nanosized GO to give methylene blue (MB), a hydrophilic and positively charged photosensitizer for anticancer performance. They proved that the excellent conversion would have taken place due to GO. NanoGO plays the dual role of a photothermal material as well as a delivery agent for photosensitizer. Additionally, the system can be effectively deposited in the tumor area when exposed under a $650 \mathrm{~nm}$ laser via the EPR effect. During this photodynamic therapy (PDT), MB generated ROS. Afterwards, at $808 \mathrm{~nm}$, laser mediates heating. Therefore, Nano-MB combined with the synergetic PDT/photothermal therapy (PTT) effect was shown to be very efficient when compared to single therapy. The RGO coupled PEGylated Ru complex demonstrated thermal and $\mathrm{pH}$ effects on the generation of ROS while releasing performance. Enhanced tumor inhibition was achieved via the syBy combined PDT/PTT that they achieved, which holds great promise in tumor therapy application. Recently, IR 808 , which is an organic dye that can be used simultaneously 
as a PDT and PTT photosensitizer, was used for combined PDT/PTT using a single $808 \mathrm{~nm}$ laser (Figure 4) [75]. NGO-PEG-BPEI has been employed as a vector for IR 808 (NGO-808), which acts as a good chemotherapeutic agent and contributes to prolonged blood circulation and specific tumor targeting and photothermal therapy. High-yield ROS and local hyperthermia that result from NGO-808 can efficiently kill tumor cells, studied under $808 \mathrm{~nm}$ laser irradiation, realizing optimal phototherapy performance by combining PDT/PTT.
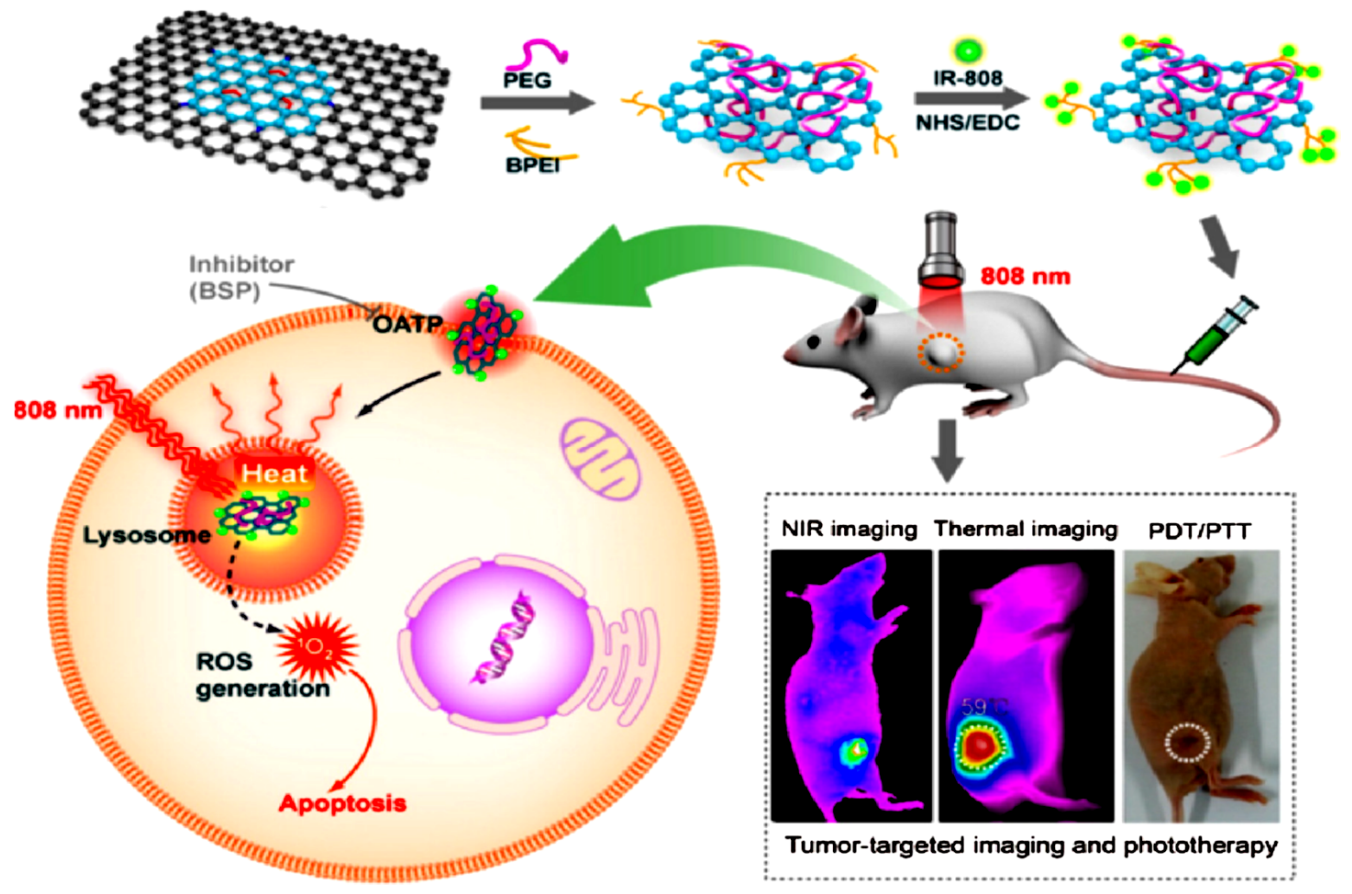

Figure 4. Schematic illustration of NGO-808 preparation and combined A549 tumor xenografts-targeted NIR imaging and synergistic phototherapy (PDT and PTT [74,75] Reprinted with permission from Elsevier.

A similar study reported that graphene-modified surfaces interact with bacteria by activating the functional and non-functional with antimicrobial peptides in graphene. A recent study clarified that a microfluidic chip that is based on optical graphene sensors is capable of detecting leukemia T-cells (single) in real-time, among normal cells responsible for immunity [44]. Another Graphene sensor was introduced to detect cancer cells, thus causing metastases. The current challenges in detecting such cells are low concentrations of the proliferation of tumor cells. Newly developed microfluidic devices can be used to identify and differentiate varieties of circulating tumor cells from the blood [76] of pancreatic, breast cancer, and lung cancer patients. In this technique, ChIP was formed with phospholipid derivatives that were modified with non-covalent functionalized GO, with specific antibodies being attached to the respective antigens. Such Graphene devices can be used for future generation flexible implants to detect cancer cells.

The CNT has been significantly considered to be a sensing element to find or detect and assess several diseases, specifically diabetes and infectious diseases. Punbusayakul et al. [64] used an electrochemical based sensor for immune complexes for Salmonella detection within a shorter time than the common method. Another immune sensor, such as adiponectin, which has been developed for obesity biomarkers, was generated from grafting antibodies on the double-walled carbon nanotubes (DWCNT) surface to immobilize them. Moreover, another antibody, such as streptavidin conjugated with horseradish peroxide (HRP) to bind with adiponectin. They react with substrate to enable detection and quantification [65]. Indeed, CNT occupancy on the surface of the electrode caused fast electron transfer and decreased the sensitivity of electrochemical detection [77]. Field-effect transistor (FET) 
based sensors have been introduced and have reported excellent sensing ability [66,78]. The present time resistive pulse sensor (RPS) based on MNCNT was used and their efficacy reaching single molecular level detection at the threshold. Another recent study has reported that the immobilized molecules can be stabilized due to the porosity. Zhang et al. described a detector nonenzymatic glucose detector that was constituted with a porous nickel-based metal oxide framework (Ni-MOF), wherein CNT acts as a good electrical conductor and enhancer. This method has been suggested as an alternate to identify the immobilization technique through immune complex [79].

\subsection{Sensing Implants}

This represented an emerging technique in bioanalytical sensors in biomedical research. They are sensing in situ implants biosensors functions in a continuous and prolonged analysis under stress in the microbiological environment. To overcome these risks, graphene-based materials enabled with surface modifications are receiving more attention as components in body implants. Peculiar characteristics of graphene-based materials, such as elasticity, chemically static better biocompatibility confer its higher performance of in vivo implants, although they are still in the initial and preclinical research stage.

\subsection{Antimicrobial Applications}

In several vaccination protocols, functionalized CNTs are being used. Studies have revealed that microarray profiling of monocytes cell lines, THP-1, exhibited functionalized, and non-functionalized CNTs induced many genes, regulating monocytes' functions to infections or vaccination. It includes (NF- KB) Nuclear factors Kappa-light chain enhancer of activated B cells interleukin-1B (1L-1B) one to six tumor necrosis factors- $\alpha$ (TNF $\alpha)$, among others [80].

Another study reported that CNTs induce class II major immuno compatibility complex (MHC) to enhance antibody-based response, which in turn elevates both specificity and sensitivity. Besides, CNTs have played a crucial role in antimicrobial activity activating oxidation of the antioxidant glutathione to make increased oxidative stress on the bacterial cells leads to the killing of infectious pathogens [81]. Zhou et al. [82] have developed Dox-loaded MWCNT magneto fluorescent carbon quantum dot (CQD), a recently discovered nano-compost for chemo and photothermal treatments. Similarly, Dong Woo et al. [83] used a PEG-coated CNT-ABT 737 nano-drug to influence mitochondria was studied Chem group have introduced a gold nanoparticle-coated carbon nanotube ring (CNTR) with higher optical signal properties, which lead to the progress of the photoacoustic signal and photothermal changing properties of the CNTR at Au was analyzed [84]. The surface level resonance (SPR) absorption from gold in SWNT-AU-PEG-FA showed better anticancer efficiency [85,86]. Graphene Quantum Dots (GQDs) with basal planes that are similar to those of graphene oxide sheets are lacking an antibacterial property, which is prepared by rupturing the C60 cage, which effectively kills ${ }^{\circ}$ Staphylococcus aureus, including its antibiotic-tolerant persisters, but not ${ }^{\circ}$ Bacillus subtilis, ${ }^{\circ}$ Escherichia coli, or ${ }^{\circ}$ Pseudomonas aeruginosa. The observed activity might correlate with a GQD's ability to disrupt the bacterial cell envelope and it is the initial step for cell envelope disruption, suggesting the importance of GQDs' chemical composition and shapes.

\section{Diagnosis}

Early detection is vital for effective therapy; well-developed detection methods are required and should be appropriate. The biomarkers that were used for in vitro analysis contribute substantial accuracy, but the long process takes time. With the electronic properties of CNT, several teams have developed CNT as the key element of electrochemical sensors, and various label-free CNT biosensors have been introduced. CNT represents a contrast agent in many bioimaging measures [87]. 
Table 1. Showing the list of recently developed carbon-based nanomaterial used in anti-cancer therapy.

\begin{tabular}{|c|c|c|c|}
\hline Carbon-based Nanomaterials & Target & Therapy & Reference \\
\hline $\begin{array}{c}\text { CNT based: } \\
\text { SWCNTs-Ru(II) complexes }\end{array}$ & Anticancer & $\begin{array}{l}\text { photothermal and } \\
\text { photodynamic therapies }\end{array}$ & {$[88]$} \\
\hline SWCNT-PEG complex & $\begin{array}{l}\text { prolonged retention in } \\
\text { blood circulation }\end{array}$ & Anticancer therapy & [89] \\
\hline $\begin{array}{c}\text { iRGD Polyethyleneimine (PE1) } \\
\text { MWCNT + Candesartan (iRGD } \\
\text { PE1-MWCNT-CD) }\end{array}$ & $\begin{array}{l}\text { inhibiting angiogenesis } \\
\text { effectively }\end{array}$ & lung cancer therapy & [63] \\
\hline GdN@CQDs-MWCNTS/DOX-EGFR & $\begin{array}{l}\text { Suppression of Tumor } \\
\text { volume }\end{array}$ & $\begin{array}{l}\text { Photothermal } \\
\text { therapy }\end{array}$ & {$[82]$} \\
\hline DOX-TAT/CHITOSAN + MWCNT & Chemotherapy & Anticancer & [90] \\
\hline CNT & Radiation treatment & phototherapy & [91] \\
\hline $\begin{array}{c}\text { GD2 monoclonal antibody } \\
\text { (anti-GD2) was conjugated to } \\
\text { acidified CNTs }\end{array}$ & Anticancer & immunotherapy & [92] \\
\hline SWCNT-PTX & $\begin{array}{l}\text { Suppressing growth } \\
\text { tumor in } 471 \text { Cells }\end{array}$ & $\begin{array}{l}\text { Breast cancer } \\
\text { therapy }\end{array}$ & [84] \\
\hline Fe@MWCNT & $\begin{array}{l}\text { in vitro cytotoxicity and } \\
\text { proapoptotic activity }\end{array}$ & Anticancer & [93] \\
\hline PEG decorated CNT ABT 737 & - & Anticancer & [83] \\
\hline \multicolumn{4}{|l|}{$\begin{array}{l}\text { GRAPHENE OXIDE BASED } \\
\text { MATERIALS }\end{array}$} \\
\hline $\begin{array}{l}\text { Porphyrin immobilized } \\
\text { nanographene oxide }\end{array}$ & - & Photo Thermal & [46] \\
\hline $\begin{array}{l}\text { Graphene Oxide with } \\
\text { double network }\end{array}$ & - & Chemo photothermal & [94] \\
\hline $\begin{array}{l}\text { Graphene Oxide conjugated with } \\
\text { PEG complex }\end{array}$ & - & Photodynamic therapy & [27] \\
\hline $\begin{array}{l}\text { TGD covered with } \\
\text { graphene carbon }\end{array}$ & - & Photodynamic & [95] \\
\hline $\begin{array}{l}\text { PEGylated GO with } \\
\text { camptothecin Analogue }\end{array}$ & Drug delivery & Anticancer Therapy & [28] \\
\hline
\end{tabular}

\section{Tissue Engineering}

The targeting of CNT on living cells exerts greater significance as a CNT used as base materials for biomedical applications. For instance, Lovat et al. demonstrated that CNT has been shown to be a good surface for cellular development and confer the effect on neural signal transmission [96]. Beduer et al. [97] demonstrated that neurons tend to grow on DWCNT compared to the $\mathrm{SiO}_{2}$ surface. Due to surface structure and found to be high affinity with culture medium protein, allowing for them to form neuron networks. A study speculated that CNT activates cell differentiation to the maximum during the growth in on DWCNT. Non-functionalized aligned MWCNT have withstood the growth and proliferation of pancreatic cancer cells, which pave the way for an innovative approach for the study of different kinds of cancer cells [98]. Correa-Daurate et al. [99] underlined that the ability of CNT to form 3D architecture to elevate proliferation and tissue engineering. Different varieties of CNT-based scaffold supporting colonization were reported [100]. 


\section{Concluding Remarks}

In the present review, current applications of carbon nano-based materials in the biomedical field have been reviewed. Their structure, shape, and size of the materials, surface chemical property. Interaction with biomolecules and therapeutic agents are collectively considered to be driving forces in the pathway of biological strength. However, the cytotoxicity effects of $\mathrm{G}$ and GO are highly debatable in recent times. However, still, interest in their unique properties is growing. The possible applications in biomedical research were received covering use in drug delivery; biosensors and cancer therapies were highlighted. This review provides strong favor to nanomaterials and expressed certain critical aspects to be focused on in future biomedical applications.

Funding: This work was supported by the National Natural Science Foundation of China (No.11674085).

Conflicts of Interest: The authors declare no conflict of interest.

\section{References}

1. Auffan, M.; Rose, J.; Bottero, J.-Y.; Lowry, G.V.; Jolivet, J.-P.; Wiesner, M.R. Towards a definition of inorganic nanoparticles from an environmental, health and safety perspective. Nat. Nanotechnol. 2009, 4, 634-641. [CrossRef] [PubMed]

2. Juliette, S.; Emmanuel, F.; Muriel, G. Overview of carbon nanotubes for biomedical applications. Materials 2019, 12, 624 .

3. Wick, P.; Louw-Gaume, A.E.; Kucki, M.; Krug, H.F.; Kostarelos, K.; Fadeel, B.; Dawson, K.A.; Salvati, A.; Vázquez, E.; Ballerini, L.; et al. Classification framework for graphene-based materials. Angew. Chem. Int. Ed. 2014, 53, 7714-7718. [CrossRef] [PubMed]

4. Neves, V.; Heister, E.; Costa, S.; Tîlmaciu, C.; Flahaut, E.; Soula, B.; Coley, H.M.; McFadden, J.; Silva, S.R.P. Design of double-walled carbon nanotubes for biomedical applications. Nanotechnology 2012, 23, 365102. [CrossRef]

5. Singh, S.R.; Vardharajula, S.; Tiwari, P.M.; Eroğlu, E.; Vig, K.; Dennis, V.A.; Ali, S.Z. Functionalized carbon nanotubes: Biomedical applications. Int. J. Nanomed. 2012, 7, 5361-5374. [CrossRef] [PubMed]

6. Geim, A.K.; Novoselov, K.S. The rise of graphene. Nat. Mater. 2007, 6, 183-191. [CrossRef]

7. ISO. ISO/TS 80004-13:2017. In Nanotechnologies-Vocabulary-Part 13: Graphene and Related Two-Dimensional (2D) Materials ISO/TS; International Organization for Standardization: Geneva, Switzerland, 2017.

8. Morozov, S.V.; Novoselov, K.S.; Katsnelson, M.I.; Schedin, F.; Elias, D.C.; Jaszczak, J.A.; Geim, A.K. Giant intrinsic carrier mobilities in graphene and its bilayer. Phys. Rev. Lett. 2008, 100, 016602. [CrossRef]

9. Balandin, A.A.; Ghosh, S.; Bao, W.-Z.; Calizo, I.; Teweldebrhan, D.; Miao, F.; Lau, C.N. Superior thermal conductivity of single-layer graphene. Nano Lett. 2008, 8, 902-907. [CrossRef]

10. Nair, R.R.; Wu, H.; Jayaram, P.N.; Grigorieva, I.V.; Geim, A.K. Unimpeded permeation of water through helium-leak-tight graphene-based membranes. Science 2012, 335, 442-444. [CrossRef]

11. Wu, J.; Chen, A.; Qin, M.; Huang, R.; Zhang, G.; Xue, B.; Wei, J.; Li, Y.; Cao, Y.; Wang, W. Hierarchical construction of a mechanically stable peptide-graphene oxide hybrid hydrogel for drug delivery and pulsatile triggered release in vivo. Nanoscale 2015, 7, 1655-1660. [CrossRef]

12. Luo, X.; Weaver, C.L.; Tan, S.; Cui, X.T. Pure graphene oxide doped conducting polymer nanocomposite for bio-interfacing. J. Mater. Chem. B 2013, 1, 1340-1348. [CrossRef] [PubMed]

13. Goenka, S.; Sant, V.; Sant, S. Graphene-based nanomaterials for drug delivery and tissue engineering. J. Control. Release 2014, 173, 75-88. [CrossRef] [PubMed]

14. Liu, S.; Zeng, T.H.; Hofmann, M.; Burcombe, E.; Wei, J.; Jiang, R.; Kong, J.; Chen, Y. Antibacterial activity of graphite, graphite oxide, graphene oxide, and reduced graphene oxide: Membrane and oxidative stress. ACS Nano 2011, 5, 6971-6980. [CrossRef] [PubMed]

15. Paul, A.; Hasan, A.; Al Kindi, H.; Gaharwar, A.K.; Rao, V.T.S.; Nikkhah, M.; Shin, S.R.; Krafft, D.; Dokmeci, M.R.; Shum-Tim, M.; et al. Injectable graphene oxide/hydrogel-based angiogenic gene delivery system for vasculogenesis and cardiac repair. ACS Nano 2014, 8, 8050-8062. [CrossRef]

16. Zuchowska, A.; Chudy, M.; Dybko, A.; Brzozka, Z. Graphene as a new material in anticancer therapy-in vitro studies. Sens. Actuators B Chem. 2017, 243, 152-165. [CrossRef] 
17. Rourke, J.; Pandey, P.A.; Moore, J.J.; Bates, M.; Kinloch, I.A.; Young, R.J.; Wilson, N.R. The real graphene oxide revealed: Stripping the oxidative debris from the graphene-like sheets. Angew. Chem. Int. Ed. 2011, 50, 3173-3177. [CrossRef] [PubMed]

18. Coleman, B.R.; Knight, T.; Gies, V.; Jakubek, Z.; Zou, S. Manipulation and quantification of graphene oxide flake size: Photoluminescence and cytotoxicity. ACS Appl. Mater. Interfaces 2017, 9, 28911-28921. [CrossRef]

19. IUPAC. Compendium of Chemical Terminology, 2nd ed.; Blackwell Scientific Publications: Oxford, UK, 1997.

20. Li, G.; Yang, Y.; Zhou, R.; Meng, F.; Li, X. Functionalized Graphene Oxide as a nanocarrier of new Copper (II) complexes for targeted therapy on nasopharyngeal carcinoma. Eur. J. Pharm. Sci. 2018, 123, 249-259. [CrossRef]

21. Chandler, D.L. Porous, 3-D Forms of Graphene Developed at MIT Can Be 10 Times as Strong as Steel but Much Lighter. Available online: https://phys.org/news/2017-01-porous-d-graphene-mit-strong.html (accessed on 1 September 2018).

22. Zheng, X.; Lee, H.; Weisgraber, T.H.; Shusteff, M.; DeOtte, J.; Duoss, E.B.; Kuntz, J.D.; Biener, M.M.; Ge, Q.; Jackson, J.A.; et al. Ultralight, ultrastiff mechanical metamaterials. Science 2014, 344, 1373-1377. [CrossRef]

23. Gupta, S.; Tai, N.-H. Carbon materials as oil sorbents: A review on the synthesis and performance. J. Mater. Chem. A 2016, 4, 1550-1565. [CrossRef]

24. Lee, H.; Rho, J.; Messersmith, P. Facile conjugation of biomolecules onto surfaces via mussel adhesive protein inspired coatings. Adv. Mater. 2009, 21, 431-434. [CrossRef]

25. Asha, S.; Ananth, A.N.; Jose, S.P.; Rajan, M.A.J. Reduced graphene oxide aerogel networks with soft interfacial template for applications in bone tissue regeneration. Appl. Nanosci. 2018, 8, 395-405. [CrossRef]

26. Wychowaniec, J.K.; Iliut, M.; Zhou, M.; Moffat, J.; ElSawy, M.A.; Pinheiro, W.A.; Hoyland, J.A.; Miller, A.F.; Vijayaraghavan, A.; Saiani, A. Designing peptide/graphene hybrid hydrogels through fine-tuning of molecular interactions. Biomacromolecules 2018, 19, 2731-2741. [CrossRef] [PubMed]

27. Zhang, Q.; Wu, Z.; Li, N.; Pu, Y.; Wang, B.; Zhang, T.; Tao, J. Advanced review of graphene-based nanomaterials in drug delivery systems: Synthesis, modification, toxicity and application. Mater. Sci. Eng. C 2017, 77, 1363-1375. [CrossRef] [PubMed]

28. Liu, Z.; Robinson, J.T.; Sun, X.; Dai, H. PEGylated Nanographene Oxide for Delivery of Water-Insoluble Cancer Drugs. J. Am. Chem. Soc. 2008, 130, 10876-10877. [CrossRef] [PubMed]

29. Dreyer, D.R.; Ruoff, R.S.; Bielawski, C.W. From conception to realization: An historial account of graphene and some perspectives for its future. Angew. Chem. Int. Ed. 2010, 49, 9336-9344. [CrossRef]

30. Hirlekar, R.; Yamagar, M.; Garse, H. Carbon nanotubes and its applications: A review. Asian J. Pharm. Clin. Res. 2009, 2, 17-27.

31. Cha, C.; Shin, S.R.; Annabi, N.; Dokmeci, M.R.; Khademhosseini, A. Carbon-Based Nanomaterials: Multifunctional Materials for Biomedical Engineering. ACS Nano 2013, 7, 2891-2897. [CrossRef]

32. Wang, J. Carbon-nanotube based electrochemical biosensors: A review. Electroanalysis 2005, 17, 7-14. [CrossRef]

33. Tonelli, F.M.P.; Goulart, V.A.; Gomes, K.N.; Ladeira, M.S.; Santos, A.; Lorençon, E.; Ladeira, L.O.; Resende, R.R. Graphene-based nanomaterials: Biological and medical applications and toxicity. Nanomedicine 2015, 10, 2423-2450. [CrossRef]

34. Yoo, J.M.; Kang, J.H.; Hong, B.H. Graphene-based nanomaterials for versatile imaging studies. Chem. Soc. Rev. 2015, 44, 4835-4852. [CrossRef]

35. Lamberti, M.; Zappavigna, S.; Sannolo, N.; Porto, S.; Caraglia, M. Advantages and risks of nanotechnologies in cancer patients and occupationally exposed workers. Expert Opin. Drug Deliv. 2014, 11, 1087-1101. [CrossRef] [PubMed]

36. Patole, S.; Alegaonkar, P.; Lee, H.-C.; Yoo, J.B. Optimization of water assisted chemical vapor deposition parameters for super growth of carbon nanotubes. Carbon 2008, 46, 1987-1993. [CrossRef]

37. Song, M.; Giovannucci, E. Cancer risk: Many factors contribute. Science 2015, 347, 728-729. [CrossRef] [PubMed]

38. Barahuie, F.; Saifullah, B.; Dorniani, D.; Fakurazi, S.; Karthivashan, G.; Hussein, M.Z.; Elfghi, F.M.; Saifullah, B.; El-Fagaih, F.M.A. Graphene oxide as a nanocarrier for controlled release and targeted delivery of an anticancer active agent, chlorogenic acid. Mater. Sci. Eng. C 2017, 74, 177-185. [CrossRef]

39. Rao, Z.; Ge, H.; Liu, L.; Zhu, C.; Min, L.; Liu, M.; Fan, L.; Li, D. Carboxymethyl cellulose modified graphene oxide as pH-sensitive drug delivery system. Int. J. Boil. Macromol. 2018, 107, 1184-1192. [CrossRef] 
40. Maria, C.C.; Slavko, K.; Marina, K.; Massimo, U.; Silvia, M. Luminescent supramolecular hydrogels from a tripeptide and nitrogen-doped carbon nanodots. Beilstein J. Nanotechnol. 2017, 8, 1553-1562.

41. Hu, X.; Li, D.; Tan, H.; Pan, C.; Chen, X. Injectable graphene oxide/graphene composite supramolecular hydrogel for delivery of anti-cancer drugs. J. Macromol. Sci. Part A 2014, 51, 378-384. [CrossRef]

42. Choi, Y.-J.; Gurunathan, S.; Kim, J.-H. Graphene Oxide-Silver Nanocomposite Enhances Cytotoxic and Apoptotic Potential of Salinomycin in Human Ovarian Cancer Stem Cells (OvCSCs): A Novel Approach for Cancer Therapy. Int. J. Mol. Sci. 2018, 19, 710. [CrossRef]

43. Servant, A.; Bianco, A.; Prato, M.; Kostarelos, K. Graphene for multi-functional synthetic biology: The last 'zeitgeist' in nanomedicine Bioorg. Med. Chem. Lett. 2014, 24, 1638-1649. [CrossRef]

44. Cheng, C.; Li, S.; Thomas, A.; Kotov, N.A.; Haag, R. Functional Graphene Nanomaterials Based Architectures: Biointeractions, Fabrications, and Emerging Biological Applications. Chem. Rev. 2017, 117, 1826-1914. [CrossRef] [PubMed]

45. Russier, J.; León, V.; Orecchioni, M.; Hirata, E.; Virdis, P.; Fozza, C.; Sgarrella, F.; Cuniberti, G.; Prato, M.; Vázquez, E.; et al. Few-Layer Graphene Kills Selectively Tumor Cells from Myelomonocytic Leukemia Patients. Angew. Chem. Int. Ed. 2017, 56, 3014-3019. [CrossRef] [PubMed]

46. Su, S.; Wang, J.; Vargas, E.; Wei, J.; Martinez-Zaguilan, R.; Sennoune, S.R.; Pantoya, M.L.; Wang, S.; Chaudhuri, J.; Qiu, J. Porphyrin Immobilized Nanographene Oxide for Enhanced and Targeted Photothermal Therapy of Brain Cancer. ACS Biomater. Sci. Eng. 2016, 2, 1357-1366. [CrossRef]

47. Dimiev, A.; Tour, J.M. Mechanism of Graphene Oxide Formation. ACS Nano 2014, 8, 3060-3068. [CrossRef]

48. Yang, K.; Feng, L.; Shi, X.; Liu, Z. Nano-graphene in biomedicine: Theranostic applications. Chem. Soc. Rev. 2013, 42, 530-547. [CrossRef]

49. Makharza, S.; Cirillo, G.; Bachmatiuk, A.; Ibrahim, I.; Ioannides, N.; Trzebicka, B.; Hampel, S.; Rümmeli, M.H. Electrochemical sensing of glucose by chitosan modified graphene oxide. J. Nanopart. Res. 2013, 15, 2099. [CrossRef]

50. Nasrollahi, F.; Varshosaz, J.; Khodadadi, A.A.; Lim, S.; Jahanian-Najafabadi, A. Targeted Delivery of Docetaxel by Use of Transferrin/Poly(allylamine hydrochloride)-functionalized Graphene Oxide Nanocarrier. ACS Appl. Mater. Interfaces 2016, 8, 13282-13293. [CrossRef]

51. Song, S.; Shen, H.; Wang, Y.; Chu, X.; Xie, J.; Zhou, N.; Shen, J. Biomedical application of graphene: From drug delivery, tumor therapy, to theranostics. Colloids Surf. B Biointerfaces 2019, 185, 110596. [CrossRef]

52. Ren, H.; Tang, M.; Guan, B.; Wang, K.; Yang, J.; Wang, F.; Wang, M.; Shan, J.; Chen, Z.; Wei, D.; et al. Hierarchical Graphene Foam for Efficient Omnidirectional Solar-Thermal Energy Conversion. Adv. Mater. 2017, 29, 1702590. [CrossRef]

53. Liu, F.; Lee, C.W.; Im, J.S. Graphene-based carbon materials for electrochemical energy storage. J. Nanomater. 2013, 642915. [CrossRef]

54. Nanda, S.S.; Papaefthymiou, G.C.; Yi, D.K. Functionalization of Graphene Oxide and its Biomedical Applications. Crit. Rev. Solid State Mater. Sci. 2015, 40, 291-315. [CrossRef]

55. Chung, C.; Kim, Y.-K.; Shin, D.; Ryoo, S.-R.; Hong, B.H.; Min, D.-H. Biomedical applications of graphene and graphene oxide. Acc. Chem. Res. 2013, 46, 2211-2224. [CrossRef] [PubMed]

56. Singh, Z. Applications and toxicity of graphene family nanomaterials and their composites. Nanotechnol. Sci. Appl. 2016, 9, 15-28. [CrossRef] [PubMed]

57. Wallace, P.R. The band theory of graphite. Phys. Rev. 1947, 71, 622-634. [CrossRef]

58. Cao, Y.; Luo, Y. Pharmacological and toxicological aspects of carbon nanotubes (CNTs) to vascular system: A review. Toxicol. Appl. Pharmacol. 2019, 385, 114801. [CrossRef] [PubMed]

59. Shityakov, S.; Salvador, E.; Pastorin, G.; Förster, C. Blood-brain barrier transport studies, aggregation, and molecular dynamics simulation of multiwalled carbon nanotube functionalized with fluorescein isothiocyanate. Int. J. Nanomed. 2015, 10, 1703-1713. [CrossRef] [PubMed]

60. Taghdisi, S.M.; Lavaee, P.; Ramezani, M.; Abnous, K. Reversible targeting and controlled release delivery of daunorubicin to cancer cells by aptamer-wrapped carbon nanotubes. Eur. J. Pharm. Biopharm. 2011, 77, 200-206. [CrossRef]

61. Ji, Z.; Lin, G.; Lu, Q.; Meng, L.; Shen, X.; Dong, L.; Fu, C.; Zhang, X. Targeted therapy of SMMC-7721 liver cancer in vitro and in vivo with carbon nanotubes based drug delivery system. J. Colloid Interface Sci. 2012, 365, 143-149. [CrossRef] 
62. Gottardi, R.; Douradinha, B. Carbon nanotubes as a novel tool for vaccination against infectious diseases and cancer. J. Nanobiotechnol. 2013, 11, 30. [CrossRef]

63. Su, Y.; Hu, Y.; Wang, Y.; Xu, X.; Yuan, Y.; Li, Y.; Wang, Z.; Chen, K.; Zhang, F.; Ding, X.; et al. A precisionguided MWNT mediated reawakening the sunk synergy in RAS for anti-angiogenesis lung cancer therapy. Biomaterials 2017, 139, 75-90. [CrossRef]

64. Punbusayakul, N.; Talapatra, S.; Ajayan, P.M.; Surareungchai, W. Label-free as-grown double wall carbon nanotubes bundles for Salmonella typhimuriumimmunoassay. Chem. Central J. 2013, 7, 102. [CrossRef] [PubMed]

65. Ojeda, I.; Barrejón, M.; Arellano, L.M.; González-Cortés, A.; Yáñez-Sedeño, P.; Langa, F.; Pingarrón, J.M. Grafted-double walled carbon nanotubes as electrochemical platforms for immobilization of antibodies using a metallic-complex chelating polymer: Application to the determination of adiponectin cytokine in serum. Biosens. Bioelectron. 2015, 74, 24-29. [CrossRef] [PubMed]

66. Chen, H.; Huang, J.; Fam, D.W.H.; Tok, A.I.Y. Horizontally Aligned Carbon Nanotube Based Biosensors for Protein Detection. Bioengineering 2016, 3, 23. [CrossRef] [PubMed]

67. Ramnani, P.; Gao, Y.; Ozsoz, M.; Mulchandani, A. Electronic Detection of MicroRNA at Attomolar Level with High Specificity. Anal. Chem. 2013, 85, 8061-8064. [CrossRef] [PubMed]

68. Liu, Y.; Dong, X.; Chen, P. Biological and chemical sensors based on graphene materials. Chem. Soc. Rev. 2012, 41, 2283-2307. [CrossRef] [PubMed]

69. Liu, G.; Riechers, S.; Mellen, M.C.; Lin, Y. Sensitive electrochemical detection of enzymatically generated thiocholine at carbon nanotube modified glassy carbon electrode. Electrochem. Commun. 2005, 7, 1163-1169. [CrossRef]

70. Kang, X.; Wang, J.; Wu, H.; Aksay, I.A.; Liu, J.; Lin, Y. Glucose Oxidase-graphene-chitosan modified electrode for direct electrochemistry and glucose sensing. Biosens. Bioelectron. 2009, 25, 901-905. [CrossRef]

71. Du, D.; Zou, Z.; Shin, Y.; Wang, J.; Wu, H.; Engelhard, M.; Liu, J.; Aksay, I.A.; Lin, Y. Sensitive immunosensor for cancer biomarker based on dual signal amplification strategy of graphene sheets and multienzyme functionalized carbon nanospheres. Anal. Chem. 2010, 82, 2989-2995. [CrossRef]

72. Tiwari, J.N.; Vij, V.; Kemp, K.; Kim, K.S. Engineered carbon-nanomaterial-based electrochemical sensors for biomolecules. ACS Nano 2015, 10, 46-80. [CrossRef]

73. Dong, H.; Zhao, Z.; Wen, H.; Guo, F.; Shen, A.; Pilger, F.; Lin, C.; Shi, D. Poly(ethylene glycol) conjugated nano-graphene oxide for photodynamic therapy. Sci. China Ser. B Chem. 2010, 53, 2265-2271. [CrossRef]

74. Sahu, A.; Choi, W.-I.; Lee, J.H.; Tae, G. Graphene oxide mediated delivery of methylene blue for combined photodynamic and photothermal therapy. Biomaterials 2013, 34, 6239-6248. [CrossRef] [PubMed]

75. Luo, S.; Yang, Z.; Tan, X.; Wang, Y.; Zeng, Y.; Wang, Y.; Li, C.M.; Li, R.; Shi, C. Multifunctional Photosensitizer Grafted on Polyethylene Glycol and Polyethylenimine Dual-Functionalized Nanographene Oxide for Cancer-Targeted Near-Infrared Imaging and Synergistic Phototherapy. ACS Appl. Mater. Interfaces 2016, 8, 17176-17186. [CrossRef] [PubMed]

76. Georgakilas, V.; Tiwari, J.N.; Kemp, K.C.; Perman, J.A.; Bourlinos, A.B.; Kim, K.S.; Zboril, R. Noncovalent functionalization of graphene and graphene oxide for energy materials, biosensing, catalytic, and biomedical applications. Chem. Rev. 2016, 116, 5464-5519. [CrossRef] [PubMed]

77. Wayu, M.B.; Pannell, M.J.; Labban, N.; Case, W.S.; Pollock, J.A.; Leopold, M.C. Functionalized carbon nanotube adsorption interfaces for electron transfer studies of galactose oxidase. Bioelectrochemistry 2019, 125, 116-126. [CrossRef] [PubMed]

78. Majd, S.M.; Salimi, A. Ultrasensitive flexible FET-type aptasensor for CA 125 cancer marker detection based on carboxylated multiwalled carbon nanotubes immobilized onto reduced graphene oxide film. Anal. Chim. Acta 2018, 1000, 273-282. [CrossRef]

79. Xu, Y.; Xu, Y.; Ye, B. An efficient electrochemical glucose sensor based on porous nickel-based metal organic framework/carbon nanotubes composite (Ni-MOF/CNTs). J. Alloy. Compd. 2018, 767, 651-656.

80. Peng, R.; Tang, X.S.; Li, D. Detection of Individual Molecules and Ions by Carbon Nanotube-Based Differential Resistive Pulse Sensor. Small 2018, 14, 1800013. [CrossRef]

81. Nel, A.; Mädler, L.; Velegol, D.; Xia, T.; Hoek, E.M.V.; Somasundaran, P.; Klaessig, F.; Castranova, V.; Thompson, M. Understanding biophysicochemical interactions at the nano-bio interface. Nat. Mater. 2009, 8, 543-557. [CrossRef] 
82. Zhang, D.-Y.; Zheng, Y.; Tan, C.-P.; Sun, J.-H.; Zhang, W.; Ji, L.-N.; Mao, Z.-W. Graphene Oxide Decorated with $\mathrm{Ru}(\mathrm{II})-$ Polyethylene Glycol Complex for Lysosome-Targeted Imaging and Photodynamic/Photothermal Therapy. ACS Appl. Mater. Interfaces 2017, 9, 6761-6771. [CrossRef]

83. Kim, S.-W.; Lee, Y.K.; Lee, J.Y.; Hong, J.H.; Khang, D. PEGylated anticancer-carbon nanotubes complex targeting mitochondria of lung cancer cells. Nanotechnology 2017, 28, 465102. [CrossRef]

84. Singh, S.; Mehra, N.K.; Jain, N.K. Development and Characterization of the Paclitaxel loaded Riboflavin and Thiamine Conjugated Carbon Nanotubes for Cancer Treatment. Pharm. Res. 2016, 33, 1769-1781. [CrossRef] [PubMed]

85. Wang, X.; Wang, C.; Cheng, L.; Lee, S.-T.; Liu, Z. Noble Metal Coated Single-Walled Carbon Nanotubes for Applications in Surface Enhanced Raman Scattering Imaging and Photothermal Therapy. J. Am. Chem. Soc. 2012, 134, 7414-7422. [CrossRef] [PubMed]

86. Bao, Z.; Liu, X.; Liu, Y.; Liu, H.; Zhao, K. Near-infrared light-responsive inorganic nanomaterials for photothermal therapy. Asian J. Pharm. Sci. 2016, 11, 349-364. [CrossRef]

87. Gong, H.; Peng, R.; Liu, Z. Carbon nanotubes for biomedical imaging: The recent advances. Adv. Drug Deliv. Rev. 2013, 65, 1951-1963. [CrossRef] [PubMed]

88. Zhang, P.; Huang, H.; Huang, J.; Chen, H.; Wang, J.; Qiu, K.; Zhao, D.; Ji, L.; Zeng, L.L. Noncovalent Ruthenium(II) Complexes-Single-Walled Carbon Nanotube Composites for Bimodal Photothermal and Photodynamic Therapy with Near-Infrared Irradiation. ACS Appl. Mater. Interfaces 2015, 7, 23278-23290. [CrossRef]

89. Sun, Y.; Li, Z. Aqueous dispersion of single walled carbon nanotubes stabilized by PEG modified diperylene bisimide and their application as an antibacterial agent. RSC Adv. 2017, 7, 26125-26129. [CrossRef]

90. Dong, X.; Sun, Z.; Wang, X.; Leng, X. An innovative MWCNTs/DOX/TC nanosystem for chemo-photothermal combination therapy of cancer. Nanomed. Nanotechnol. Boil. Med. 2017, 13, 2271-2280. [CrossRef]

91. Zhang, L.; Yuan, H.; Inscoe, C.R.; Chtcheprov, P.; Hadsell, M.; Lee, Y.Z.; Lu, J.; Chang, S.; Zhou, O. Nanotube $\mathrm{X}$-ray for cancer therapy: A compact microbeam radiation therapy system for brain tumor treatment. Expert Rev. Anticancer. Ther. 2014, 14, 1411-1418. [CrossRef]

92. Wang, C.H.; Huang, Y.J.; Chang, C.W.; Hsu, W.M.; Peng, C.A. In vitro photothermal destruction of neuroblastoma cells using carbon nanotubes conjugated with GD2 monoclonal antibody. Nanotechnology 2009, 20, 315101. [CrossRef]

93. Boncel, S.; Pluta, A.; Skonieczna, M.; Gondela, A.; Maciejewska, B.; Herman, A.P.; Jwdrysiak, R.B.G.; Budniok, S.; Komwdera, K.; Bachowski, A.B.; et al. Hybrids of iron-filled multiwall carbon nanotubes and anticancer agents as potential magnetic drug delivery systems: In vitro studies against human melanoma, colon carcinoma, and colon adenocarcinoma. J. Nanomater. 2017. [CrossRef]

94. Fiorica, C.; Mauro, N.; Pitarresi, G.; Scialabba, C.; Palumbo, F.S.; Giammona, G. Double-Network-Structured Graphene Oxide-Containing Nanogels as Photothermal Agents for the Treatment of Colorectal Cancer. Biomacromolecules 2017, 18, 1010-1018. [CrossRef] [PubMed]

95. Chen, F.; Gao, W.; Qiu, X.; Zhang, H.; Liu, L.; Liao, P.; Fu, W.; Luo, Y. Graphene quantum dots in biomedical applications: Recent advances and future challenges. Front. Lab. Med. 2017, 1, 192-199. [CrossRef]

96. Lovat, V.; Pantarotto, D.; Lagostena, L.; Cacciari, B.; Grandolfo, M.; Righi, M.; Spalluto, G.; Prato, M.; Ballerini, L. Carbon Nanotube Substrates Boost Neuronal Electrical Signaling. Nano Lett. 2005, 5, 1107-1110. [CrossRef] [PubMed]

97. Béduer, A.; Seichepine, F.; Flahaut, E.; Loubinoux, I.; Vaysse, L.; Vieu, C. Elucidation of the Role of Carbon Nanotube Patterns on the Development of Cultured Neuronal Cells. Langmuir 2012, 28, 17363-17371. [CrossRef]

98. Matta-Domjan, B.; King, A.; Totti, S.; Matta, C.; Dover, G.; Martinez, P.; Zakhidov, A.; La Ragione, R.; Macedo, H.; Jurewicz, I.; et al. Biophysical interactions between pancreatic cancer cells and pristine carbon nanotube substrates: Potential application for pancreatic cancer tissue engineering: Pancreatic cancer on pristine CNT substrates. J. Biomed. Mater. Res. B Appl. Biomater. 2018, 106, 1637-1644. [CrossRef] 
99. Correa-Duarte, M.A.; Wagner, N.; Rojas-Chapana, J.; Morsczeck, C.; Thie, M.; Giersig, M. Fabrication and Biocompatibility of Carbon Nanotube-Based 3D Networks as Scaffolds for Cell Seeding and Growth. Nano Lett. 2004, 4, 2233-2236. [CrossRef]

100. Han, Z.; Rider, A.; Ishaq, M.; Kumar, S.; Kondyurin, A.; Bilek, M.M.M.; Levchenko, I.; Ostrikov, K. Carbon nanostructures for hard tissue engineering. RSC Adv. 2013, 3, 11058-11072. [CrossRef]

(C) 2020 by the authors. Licensee MDPI, Basel, Switzerland. This article is an open access article distributed under the terms and conditions of the Creative Commons Attribution (CC BY) license (http://creativecommons.org/licenses/by/4.0/). 